\title{
Real-world Safety Profile of Darunavir and its Boosted Agents: An Analysis of FDA Adverse Event Reporting System Database
}

\section{Xiaojiang Tian}

Department of pharmacy, Chongqing Health Center for Women and Children

\section{Yao Yao}

Department of pharmacy, Chongqing Health Center for Women and Children

\section{Guanglin He}

Department of Anthropology and Ethnology, Institute of Anthropology, National Institute for Data

Science in Health and Medicine, and School of Life Sciences, Xiamen University

\section{Yuntao Jia}

Department of Pharmacy, Children's Hospital of Chongqing Medical University

\section{Kejing Wang}

Department of pharmacy, Chongqing Health Center for Women and Children

\section{Lin Chen ( $\nabla$ clfxmm@163.com )}

Department of pharmacy, Chongqing Health Center for Women and Children

\section{Research Article}

Keywords: US Food and Drug Administration Adverse Event Reporting System (FAERS), adverse event (AE), Darunavir

Posted Date: February 24th, 2021

DOI: https://doi.org/10.21203/rs.3.rs-225287/v1

License: (c) (i) This work is licensed under a Creative Commons Attribution 4.0 International License. Read Full License 


\section{Abstract}

This current investigation was aimed to generate signals for adverse drug events of darunavir-containing agents by data mining using the US Food and Drug Administration Adverse Event Reporting System (FAERS). All adverse event (AE) reports for darunavir, darunavir/ritonavir, or darunavir/cobicistat between July 2006 and December 2019 were identified. The reporting Odds Ratio (ROR), proportional reporting ratio(PRR), Bayesian confidence propagation neural network(BCPNN) were used to detect the risk signals. A suspicious signal was generated only if the results of the three algorithms were all positive. A total of $10756 \mathrm{AE}$ reports were identified commonly observed in cardiovascular, endocrine, musculoskeletal, gastrointestinal, hepatobiliary, metabolic, and nutrition system. 40 suspicious signals were generated, and therein 20 signals were not included in the label. Severe high signals (i.e. progressive extraocular muscle paralysis, acute pancreatitis, exfoliative dermatitis, acquired lipodystrophy and mitochondrial toxicity) were identified. In pregnant women, umbilical cord abnormality, fetal growth restriction, low birth weight, stillbirth, premature rupture of membranes, premature birth and spontaneous abortion showed positive signals. Darunavir and its boosted agents induced AEs in various organs/tissues, and were shown to be associated with multiple adverse pregnancy conditions. This study highlighted some novel and severe AEs of darunavir which need to be monitored prospectively.

\section{Introduction}

The burden of morbidity and mortality associated with human immunodeficiency virus (HIV) infection has become a serious public health problem globally ${ }^{1}$. WHO and most national guidelines recommended all people living with HIV to start antiretroviral therapy (ART) irrespective of clinical or immune status ${ }^{1,2}$. Earlier initiation of ART and improved access to HIV treatment has led to an overall improvement in disease control, and the annual number of people dying from HIV-related causes has declined by $43 \%{ }^{3}$. However, the increasing use of antiretroviral agents has raised potential safety concerns of these drugs which need to be systemically analyzed.

Darunavir, a nonpeptidic inhibitor of the HIV-1 protease with potent activity against resistant virus, was initially approved by the Food and Drug Administration (FDA) in 2006 for the treatment of antiretroviralexperienced adults, and later for naive adults.

It must be co-administered with a boosting agent, either ritonavir or cobicistat. In 2008, FDA required labeling change of darunavir, warning the safety issues. In recent years, multiple studies reported the adverse events (AEs) of darunavir-containing agents related to hepatic ${ }^{4}$ and skin system ${ }^{5}$. In addition, darunavir was considered a preferred protease inhibitor for pregnant females living with HIV by the Health and Human Service (HHS) panel, its safety information during pregnancy was still under ongoing monitoring ${ }^{6}$. In 2015 , the antiretroviral pregnancy registry steering committee suggested that prenatal exposure to protease inhibitors can lead to increased risk of miscarriage and low birth weight ${ }^{7}$. Nevertheless, clinical data on pregnancy outcomes and fetal safety after darunavir exposure during pregnancy are limited. 
The primary aim of this pharmacovigilance study was to characterize the safety profile of darunavircontaining agents relating to various organ systems, moreover, evaluate the perinatal outcomes in HIV mothers exposed to darunavir during pregnancy using data-mining of FDA Adverse Event Reporting System (FAERS).

\section{Results}

Descriptive analysis. During the study period, a total of $11,170,959$ reports were submitted to FAERS, of which 10,756 for darunavir and its boosted agents. Table 3 described the characteristics of AE reports submitted for darunavir. Higher rate of male patients $(n=5898,54.47 \%)$ was reported than female patients $(n=3111,28.92 \%) ; 49.31 \%(n=5304)$ of the AEs occurred in people aged $18-60$ years; SAE accounted for a relatively high proportion $(n=4460,41.47 \%)$, with hospitalization and prolonged hospitalization being the most reported outcome $(n=3503,32.57 \%)$. 
Table 3

Characteristics of adverse event reports submitted for darunavir and its boosted agents

\begin{tabular}{|c|c|c|}
\hline & N. of reported AEs & Ratio (\%) \\
\hline \multicolumn{3}{|l|}{ Gender } \\
\hline Male & 5859 & 54.47 \\
\hline Female & 3111 & 28.92 \\
\hline Unknown & 1786 & 16.61 \\
\hline \multicolumn{3}{|l|}{ Age group, (y) } \\
\hline Q18 & 477 & 4.43 \\
\hline $18 \sim 44$ & 2490 & 23.15 \\
\hline $45 \sim 64$ & 2814 & 26.16 \\
\hline $65 \sim 74$ & 342 & 3.18 \\
\hline$\geq 75$ & 101 & 0.94 \\
\hline Unknown & 4532 & 42.13 \\
\hline \multicolumn{3}{|l|}{ Reporters } \\
\hline Doctors & 3950 & 36.72 \\
\hline Pharmacists & 1022 & 9.50 \\
\hline Other medical staff & 3628 & 33.73 \\
\hline Lawyers & 18 & 0.17 \\
\hline Consumers & 1836 & 17.07 \\
\hline Unkown & 302 & 2.81 \\
\hline \multicolumn{3}{|l|}{ SAEs $^{a}$} \\
\hline Death & 102 & 0.95 \\
\hline Life-threatening & 526 & 4.89 \\
\hline Hospitalization (initial or prolonged) & 3503 & 32.57 \\
\hline Disability & 329 & 3.06 \\
\hline
\end{tabular}

Signals of SDR and BCPNN. When AEs were classified with SOC of MedDRA, the positive signals detected by the three algorithms were consistent, involving 11 organ systems: liver, kidney, metabolic and 
nutritional system, endocrine system, eye, cardiac system, musculoskeletal system, nervous system, skin, gastrointestinal tract, and perinatal periods (Table 4).

Table 4

Involved systems and signal strength for darunavir and its boosted agents based on system organ class

\begin{tabular}{|c|c|c|c|}
\hline soc $^{a}$ & $\operatorname{ROR}^{b}(95 \% \mathrm{Cl})$ & $\operatorname{PRR}^{c}\left(\chi^{2}\right)$ & $\begin{array}{l}I^{d}(I C- \\
2 S D)\end{array}$ \\
\hline Hepatobiliary disorders & $3.03(2.88-3.20)$ & $2.72(1882.57)$ & $1.44(1.41)$ \\
\hline Renal and urinary disorders & $2.45(2.33-2.57)$ & $2.19(1341.86)$ & $1.13(1.10)$ \\
\hline Metabolism and nutrition disorders & $2.44(1.35-1.56)$ & $2.41(103.75)$ & $0.50(0.47)$ \\
\hline Endocrine disorders & $\begin{array}{l}13.92(12.43- \\
15.59)\end{array}$ & $13.55(3585.85)$ & $3.69(3.65)$ \\
\hline Eye disorders & $\begin{array}{l}21.44(18.63- \\
24.66)\end{array}$ & $21.05(3783.56)$ & $4.24(4.20)$ \\
\hline Cardiac disorders & $2.03(1.01-2.24)$ & $2.04(4.05)$ & $0.04(0.01)$ \\
\hline $\begin{array}{l}\text { Musculoskeletal and connective tissue } \\
\text { disorders }\end{array}$ & $7.96(7.33-8.65)$ & $7.58(3374.00)$ & $2.90(2.87)$ \\
\hline Nervous system disorders & $7.16(6.48-7.90)$ & $6.93(2061.09)$ & $2.76(2.73)$ \\
\hline Skin and subcutaneous tissue disorders & $\begin{array}{l}10.90(10.28- \\
11.57)\end{array}$ & 9.75 (9877.79) & $3.26(3.23)$ \\
\hline Gastrointestinal disorders & $\begin{array}{l}10.10(9.58- \\
10.65)\end{array}$ & $8.71(11314.98)$ & $3.11(3.08)$ \\
\hline $\begin{array}{l}\text { Pregnancy, puerperium and perinatal } \\
\text { conditions }\end{array}$ & $\begin{array}{l}12.63(12.05- \\
13.24)\end{array}$ & $\begin{array}{l}10.26 \\
(18528.56)\end{array}$ & $3.34(3.31)$ \\
\hline
\end{tabular}

a SOC System organ class

${ }^{b} \mathrm{ROR}$ reporting odds ratio. The lower limits of the $95 \% \mathrm{Cl}$ of the ROR greater than 1 indicated statistically significant RORs.

${ }^{c}$ PRR proportional reporting ratio. PRR and $\chi^{2}$ greater than 2 and 4 respectively indicated statistically significant PRRs.

${ }^{d}$ Information component. The signal was statistically significant when IC-2SD $>0$

Further analyses conducted at the PT level revealed 40 suspicious signals, 20 of which were not included in the label. Among them, 6 suspicious signals were generated in hepatobiliary system, including hepatocyte injury $(R O R=12.00, P R R=11.89, I C=3.42)$, hyperbilirubinemia $(R O R=7.62, P R R=7.60, I C=$ 2.73), cholestasis $(R O R=7.61, P R R=7.57, I C=2.80)$, etc; 6 signals in kidney and urinary system, including renal tubular necrosis $(\mathrm{ROR}=6.93, \mathrm{PRR}=6.91, \mathrm{IC}=2.57$ ), decreased glomerular filtration rate $(R O R=6.86, P R R=6.84, I C=2.55)$, and proteinuria $(R O R=5.44, P R R=5.75, I C=2.40)$, ect; 3 in 
metabolism and nutrition system: hypertriglyceridaemia ( $R O R=15.81, P R R=15.73, I C=3.59)$, hypercholesterolaemia $(\mathrm{ROR}=7.31, \mathrm{PRR}=7.29, \mathrm{IC}=2.63)$ and hypokalaemia $(\mathrm{ROR}=1.57, \mathrm{PRR}=2.57, \mathrm{IC}=$ $0.63) ; 1$ in cardiovascular system: blood creatine phosphokinase increased $(R O R=3.47, P R R=3.46, I C=$ 1.74); 1 in musculoskeletal system: rhabdomyolysis $(\mathrm{ROR}=3.00, \mathrm{PRR}=2.99, \mathrm{IC}=1.54) ; 4$ in skin and subcutaneous tissue: rash generalized $(R O R=2.34, P R R=2.34, I C=1.2)$, pruritus $(R O R=2.25, P R R=2.32$, $I C=0.61)$, dermatitis exfoliative $(R O R=10.26$, $P R R=10.22$, IC $=3.11)$, and Stevens-Johnson Syndrome $(R O R=3.11, P R R=3.10, I C=1.57) ; 4$ in gastrointestinal system: diarrhea $(R O R=1.21, P R R=2.23, I C=0.3)$, gastrointestinal disorder $(R O R=1.71, P R R=2.71, I C=0.76)$, oesophageal candidiasis $(R O R=16.02, P R R$ $=15.97, I C=3.5)$, and acute pancreatitis $(\mathrm{ROR}=4.21, \mathrm{PRR}=4.19, \mathrm{IC}=1.26)$.

It was worth noting that darunavir-containing agents can induce progressive ophthalmoplegia (ROR = 1761.17, $P R R=1753.15, I C=3.54)$, lipodystrophy acquired $(R O R=137.98, P R R=136.03, I C=6.08)$, mitochondrial toxicity $(R O R=171.92, P R R=136.03, I C=6.08)$, adrenal suppression $(R O R=44.60, P R R=$ $44.49, I C=4.13$ ) and other severe high strength signals (Table 5). 
Table 5

Signal strength for darunavir and its boosted agents based on PT level in FAERS

\begin{tabular}{|c|c|c|c|c|c|}
\hline $\mathrm{PTs}^{\mathrm{a}}$ & $N .^{b}$ & $\operatorname{ROR}^{c}(95 \% \mathrm{Cl})$ & $\operatorname{PRR}^{d}\left(x^{2}\right)$ & $\begin{array}{l}\text { ICe (IC- } \\
2 S D)\end{array}$ & Label $^{f}$ \\
\hline \multicolumn{6}{|l|}{ Hepatobiliary disorders } \\
\hline Hepatocellular injury & 105 & $12.00(9.89-14.56)$ & $\begin{array}{l}11.89 \\
(1025.76)\end{array}$ & $\begin{array}{l}3.42 \\
(3.38)\end{array}$ & yes \\
\hline Liver function test abnormal & 88 & $3.93(3.18-4.85)$ & $3.90(186.81)$ & $\begin{array}{l}1.91 \\
(1.88)\end{array}$ & yes \\
\hline Hepatic enzyme increased & 147 & $3.80(2.85-5.05)$ & $3.78(90.29)$ & $\begin{array}{l}1.83 \\
(1.80)\end{array}$ & yes \\
\hline Jaundice & 72 & $3.28(2.60-4.13)$ & $3.26(110.46)$ & $\begin{array}{l}1.66 \\
(1.62)\end{array}$ & no \\
\hline Cholestasis & 78 & $7.61(6.09-9.52)$ & $7.57(435.14)$ & $\begin{array}{l}2.80 \\
(2.76)\end{array}$ & no \\
\hline Hyperbilirubinaemia & 46 & $7.62(5.70-10.19)$ & $7.60(255.16)$ & $\begin{array}{l}2.73 \\
(2.68)\end{array}$ & no \\
\hline \multicolumn{6}{|l|}{ Renal and urinary disorders } \\
\hline Acute kidney injury & 164 & $2.53(2.17-2.95)$ & $2.51(148.32)$ & $\begin{array}{l}1.32 \\
(1.28)\end{array}$ & yes \\
\hline Renal impairment & 150 & $3.49(2.97-4.10)$ & $3.46(259.46)$ & $\begin{array}{l}1.32 \\
(1.29)\end{array}$ & yes \\
\hline Blood creatinine increased & 116 & $2.84(2.36-3.41)$ & $2.82(134.12)$ & $\begin{array}{l}1.49 \\
(1.44)\end{array}$ & yes \\
\hline $\begin{array}{l}\text { Glomerular filtration rate } \\
\text { decreased }\end{array}$ & 35 & $6.86(4.92-9.57)$ & $6.84(167.83)$ & $\begin{array}{l}2.55 \\
(2.50)\end{array}$ & yes \\
\hline Proteinuria & 53 & $5.44(4.40-4.57)$ & $5.75(202.23)$ & $\begin{array}{l}2.40 \\
(2.35)\end{array}$ & no \\
\hline
\end{tabular}

aPT: Preferred Terms

${ }^{b}$ Number of patients with adverse events

${ }^{c}$ ROR reporting odds ratio. The lower limits of the $95 \% \mathrm{Cl}$ of the ROR greater than 1 indicated statistically significant RORs.

d PRR proportional reporting ratio. PRR and $\chi^{2}$ greater than 2 and 4 respectively indicated statistically significant PRRs.

${ }^{e}$ Information component. The signal was statistically significant when IC-2SD >0

${ }^{f}$ Whether adverse events are mentioned in the drug label or not 


\begin{tabular}{|c|c|c|c|c|c|}
\hline PTs $s^{a}$ & N. ${ }^{b}$ & $\operatorname{ROR}^{c}(95 \% \mathrm{Cl})$ & $\operatorname{PRR}^{d}\left(\chi^{2}\right)$ & $\begin{array}{l}\text { IC (IC- } \\
2 \text { SD) }\end{array}$ & Label $^{f}$ \\
\hline Renal tubular necrosis & 37 & $6.93(5.01-9.58)$ & $6.91(180.08)$ & $\begin{array}{l}2.57 \\
(2.53)\end{array}$ & no \\
\hline \multicolumn{6}{|c|}{ Metabolism and nutrition disorders } \\
\hline Hypertriglyceridaemia & 49 & $\begin{array}{l}15.81(11.92- \\
20.98)\end{array}$ & $15.75(662.25)$ & $\begin{array}{l}3.59 \\
(3.53)\end{array}$ & yes \\
\hline Hypercholesterolaemia & 36 & $7.31(5.26-10.15)$ & 7.29 (187.79) & $\begin{array}{l}2.63 \\
(2.58)\end{array}$ & yes \\
\hline Hypokalaemia & 40 & $1.57(1.15-2.15)$ & $2.57(7.78)$ & $\begin{array}{l}0.63 \\
(0.60)\end{array}$ & no \\
\hline \multicolumn{6}{|l|}{ Endocrine disorders } \\
\hline Hyperglycaemia & 60 & $2.78(3.16-3.59)$ & $2.77(66.29)$ & $\begin{array}{l}1.43 \\
(1.39)\end{array}$ & yes \\
\hline Adrenal insufficiency & 54 & $11.89(9.08-15.56)$ & $11.83(519.06)$ & $\begin{array}{l}3.29 \\
(3.24)\end{array}$ & no \\
\hline Adrenal suppression & 28 & $\begin{array}{l}44.60(30.54- \\
65.14)\end{array}$ & $\begin{array}{l}44.49 \\
(1100.12)\end{array}$ & $\begin{array}{l}4.13 \\
(4.02)\end{array}$ & no \\
\hline \multicolumn{6}{|l|}{ Eye disorders } \\
\hline Diplopia & 63 & $4.24(3.31-5.43)$ & $4.22(151.11)$ & $\begin{array}{l}2.00 \\
(1.97)\end{array}$ & no \\
\hline Eyelid ptosis & 59 & $10.43(8.06-13.49)$ & $10.38(486.02)$ & $\begin{array}{l}3.15 \\
(3.11)\end{array}$ & no \\
\hline $\begin{array}{l}\text { Progressive external } \\
\text { ophthalmoplegia }\end{array}$ & 49 & $\begin{array}{l}1761.17(1112.25- \\
2788.69)\end{array}$ & $\begin{array}{l}1753.15 \\
(31253.87)\end{array}$ & $\begin{array}{l}3.54 \\
(3.21)\end{array}$ & no \\
\hline
\end{tabular}

aPT: Preferred Terms

${ }^{\mathrm{b}}$ Number of patients with adverse events

${ }^{\mathrm{c}} \mathrm{ROR}$ reporting odds ratio. The lower limits of the $95 \% \mathrm{Cl}$ of the ROR greater than 1 indicated statistically significant RORs.

d PRR proportional reporting ratio. PRR and $\chi^{2}$ greater than 2 and 4 respectively indicated statistically significant PRRs.

e Information component. The signal was statistically significant when IC-2SD >0

${ }^{f}$ Whether adverse events are mentioned in the drug label or not 


\begin{tabular}{|c|c|c|c|c|c|}
\hline $\mathrm{PTs}^{\mathrm{a}}$ & $N .^{b}$ & $\operatorname{ROR}^{c}(95 \% \mathrm{Cl})$ & $\operatorname{PRR}^{d}\left(x^{2}\right)$ & $\begin{array}{l}\text { ICe (IC- } \\
2 S D)\end{array}$ & Labelf $^{f}$ \\
\hline $\begin{array}{l}\text { Blood creatine phosphokinase } \\
\text { increased }\end{array}$ & 73 & $3.47(2.76-4.37)$ & $3.46(124.84)$ & $\begin{array}{l}1.74 \\
(1.70)\end{array}$ & yes \\
\hline \multicolumn{6}{|c|}{ Musculoskeletal and connective tissue disorders } \\
\hline Rhabdomyolysis & 76 & $3.00(2.39-3.76)$ & $2.99(98.36)$ & $\begin{array}{l}1.54 \\
(1.51)\end{array}$ & yes \\
\hline \multicolumn{6}{|l|}{ Nervous system disorders } \\
\hline Nervous system disorder & 45 & $1.76(1.31-2.36)$ & $3.68(235.32)$ & $\begin{array}{l}0.79 \\
(0.76)\end{array}$ & no \\
\hline Neuropathy peripheral & 119 & $2.50(2.08-3.00)$ & $2.48(103.91)$ & $\begin{array}{l}1.29 \\
(1.26)\end{array}$ & no \\
\hline \multicolumn{6}{|c|}{ Skin and subcutaneous tissue disorders } \\
\hline Rash generalised & 74 & $2.34(1.87-2.95)$ & $2.34(55.32)$ & $\begin{array}{l}1.20 \\
(1.17)\end{array}$ & yes \\
\hline Pruritus & 44 & $2.55(1.15-2.09)$ & $2.32(54.21)$ & $\begin{array}{l}0.61 \\
(0.58)\end{array}$ & yes \\
\hline Dermatitis exfoliative & 53 & $10.26(7.83-13.46)$ & $10.22(46.74)$ & $\begin{array}{l}3.11 \\
(3.07)\end{array}$ & yes \\
\hline Stevens-Johnson Syndrome & 47 & $3.11(2.33-4.14)$ & $3.10(64.68)$ & $\begin{array}{l}1.57 \\
(1.53)\end{array}$ & yes \\
\hline \multicolumn{6}{|l|}{ Gastrointestinal disorders } \\
\hline Diarrhoea & 405 & $1.21(1.12-1.37)$ & $2.23(18.11)$ & $\begin{array}{l}0.30 \\
(0.27)\end{array}$ & yes \\
\hline Gastrointestinal disorder & 84 & $1.71(1.38-2.12)$ & $2.71(24.03)$ & $\begin{array}{l}0.76 \\
(0.73)\end{array}$ & yes \\
\hline
\end{tabular}

\section{aPT: Preferred Terms}

${ }^{b}$ Number of patients with adverse events

${ }^{c}$ ROR reporting odds ratio. The lower limits of the $95 \% \mathrm{Cl}$ of the ROR greater than 1 indicated statistically significant RORs.

d PRR proportional reporting ratio. PRR and $\chi^{2}$ greater than 2 and 4 respectively indicated statistically significant PRRs.

e Information component. The signal was statistically significant when IC-2SD >0

${ }^{f}$ Whether adverse events are mentioned in the drug label or not 


\begin{tabular}{|c|c|c|c|c|c|}
\hline PTs ${ }^{a}$ & N. ${ }^{b}$ & $\operatorname{ROR}^{c}(95 \% \mathrm{Cl})$ & $\operatorname{PRR}^{d}\left(x^{2}\right)$ & $\begin{array}{l}\text { ICe }(I C- \\
2 S D)\end{array}$ & Label $^{f}$ \\
\hline Oesophageal candidiasis & 37 & $\begin{array}{l}16.02(11.57- \\
22.18)\end{array}$ & $15.97(496.77)$ & $\begin{array}{l}3.50 \\
(3.44)\end{array}$ & no \\
\hline Pancreatitis acute & 59 & $4.21(3.26-8.44)$ & $4.19(139.96)$ & $\begin{array}{l}1.26 \\
(1.23)\end{array}$ & yes \\
\hline \multicolumn{6}{|l|}{ Others } \\
\hline Virologic failure & 254 & $\begin{array}{l}117.48(103.06- \\
133.93)\end{array}$ & $\begin{array}{l}114.73 \\
(256.88)\end{array}$ & $\begin{array}{l}6.02 \\
(6.14)\end{array}$ & no \\
\hline Drug resistance & 224 & $\begin{array}{l}17.31(15.15- \\
19.78)\end{array}$ & $\begin{array}{l}16.97 \\
(3301.72)\end{array}$ & $\begin{array}{l}3.97 \\
(3.93)\end{array}$ & no \\
\hline Lipodystrophy acquired & 153 & $\begin{array}{l}137.98(116.46- \\
163.48)\end{array}$ & $\begin{array}{l}136.03 \\
(18013.82)\end{array}$ & $\begin{array}{l}6.08 \\
(6.00)\end{array}$ & no \\
\hline Viral mutation identified & 75 & $\begin{array}{l}52.98(41.98- \\
66.86)\end{array}$ & $\begin{array}{l}52.62 \\
(3565.80)\end{array}$ & $\begin{array}{l}4.93 \\
(4.85)\end{array}$ & no \\
\hline Mitochondrial toxicity & 68 & $\begin{array}{l}171.92(132.93- \\
222.34)\end{array}$ & $\begin{array}{l}107.84 \\
(9713.13)\end{array}$ & $\begin{array}{l}5.56 \\
(5.42)\end{array}$ & no \\
\hline Angioedema & 42 & $1.47(1.09-1.99)$ & $2.47(15.84)$ & $\begin{array}{l}0.54 \\
(0.51)\end{array}$ & yes \\
\hline Erectile dysfunction & 29 & $2.03(1.41-2.93)$ & $2.03(14.19)$ & $\begin{array}{l}0.97 \\
(0.94)\end{array}$ & no \\
\hline \multicolumn{6}{|l|}{ aPT: Preferred Terms } \\
\hline \multicolumn{6}{|c|}{${ }^{\mathrm{b}}$ Number of patients with adverse events } \\
\hline \multicolumn{6}{|c|}{$\begin{array}{l}{ }^{c} \text { ROR reporting odds ratio. The lower limits of the } 95 \% \mathrm{Cl} \text { of the ROR greater than } 1 \text { indicated } \\
\text { statistically significant RORs. }\end{array}$} \\
\hline \multicolumn{6}{|c|}{$\begin{array}{l}\text { d PRR proportional reporting ratio. PRR and } \chi^{2} \text { greater than } 2 \text { and } 4 \text { respectively indicated statistically } \\
\text { significant PRRs. }\end{array}$} \\
\hline \multicolumn{6}{|c|}{ e Information component. The signal was statistically significant when IC-2SD >0 } \\
\hline
\end{tabular}

Among pregnant women, umbilical cord abnormality ( $R O R=71.32$, $P R R=71.13$, IC $=4.38$ ), foetal growth restriction $(R O R=37.37, P R R=37.02, I C=4.75)$, low birth weight baby $(R O R=26.54, P R R=26.31, I C=$ 4.35), stillbirth $(R O R=22.59, P R R=22.45, I C=4.09)$, premature rupture of membrane $(R O R=17.20, P R R=$ $17.14, I C=3.58)$, premature baby $(R O R=16.50, P R R=16.11, I C=3.91)$ and abortion spontaneous (ROR = $10.87, \mathrm{PRR}=10.62, \mathrm{IC}=3.35$ ) showed positive signals (Table 6$)$. When detected separately, signals of abortion spontaneous $(R O R=5.39, P R R=5.33, I C=1.93)$ and foetal growth restriction $(R O R=120.7, P R R$ 
$=116.93, \mathrm{IC}=4.42)$ for darunavir/cobicistat were positive, and premature baby $(\mathrm{ROR}=1.98, \mathrm{PRR}=1.98$, $\mathrm{IC}=0.38$ ) for darunavir/ritonavir positive (Table 7).

Table 6

Signal strength of pregnancy, puerperium and perinatal conditions for darunavir and its boosted agents

\begin{tabular}{|c|c|c|c|c|}
\hline $\mathrm{PT}^{\mathrm{a}}$ & $N .^{b}$ & $\operatorname{ROR}^{c}(95 \% \mathrm{Cl})$ & $\operatorname{PRR}^{\mathrm{d}}\left(\chi^{2}\right)$ & IC $(I C-2 S D)$ \\
\hline $\begin{array}{l}\text { Foetal exposure during } \\
\text { pregnancy }\end{array}$ & 813 & $20.73(19.28-22.28)$ & $19.24(13836.29)$ & $4.21(4.18)$ \\
\hline Premature baby & 272 & $16.50(14.62-18.63)$ & $16.11(3789.36)$ & $3.91(3.88)$ \\
\hline Abortion spontaneous & 269 & $10.87(9.63-12.28)$ & $10.62(2317.55)$ & $3.35(3.31)$ \\
\hline Foetal growth restriction & 105 & $37.37(30.73-45.45)$ & $37.02(3519.26)$ & $4.75(4.69)$ \\
\hline Low birth weight baby & 95 & $26.54(21.13-32.56)$ & $26.31(2232.29)$ & $4.35(4.30)$ \\
\hline Stillbirth & 70 & $22.59(17.81-28.65)$ & $22.45(1383.80)$ & $4.09(4.03)$ \\
\hline Premature rupture of membranes & 38 & $17.20(12.48-23.71)$ & $17 . .14(552.58)$ & $3.58(3.52)$ \\
\hline Umbilical cord abnormality & 29 & $\begin{array}{l}71.32(48.94- \\
103.95)\end{array}$ & $71.13(1811.59)$ & $4.38(4.25)$ \\
\hline
\end{tabular}

aPT: Preferred Terms

${ }^{b}$ Number of patients with adverse events

${ }^{c}$ ROR reporting odds ratio. The lower limits of the $95 \% \mathrm{Cl}$ of the ROR greater than 1 indicated statistically significant RORs.

d PRR proportional reporting ratio. PRR and $\chi^{2}$ greater than 2 and 4 respectively indicated statistically significant PRRs.

e Information component. The signal was statistically significant when IC-2SD >0 
Table 7

Signal strengthof pregnancy, puerperium and perinatal conditions for darunavir/cobicistat and darunavir/ritonavir

\begin{tabular}{|c|c|c|c|c|c|c|c|c|}
\hline \multirow[b]{2}{*}{$\mathrm{PT} \mathrm{T}^{\mathrm{a}}$} & \multicolumn{4}{|c|}{ Darunavir/cobicistat } & \multicolumn{4}{|c|}{ Darunavir/ritonavir } \\
\hline & $\mathrm{N}^{\mathrm{b}}$ & $\begin{array}{l}\mathrm{ROR}^{\mathrm{C}}(95 \% \\
\mathrm{Cl})\end{array}$ & $\operatorname{PRR}^{d}\left(\chi^{2}\right)$ & $\begin{array}{l}\text { IC }(I C- \\
2 S D)\end{array}$ & $\mathrm{N}$ & $\begin{array}{l}\text { ROR } \\
(95 \% \\
\text { Cl) }\end{array}$ & $\begin{array}{l}\text { PRR } \\
(\mathrm{X} 2)\end{array}$ & $\begin{array}{l}\text { IC (IC- } \\
2 S D)\end{array}$ \\
\hline $\begin{array}{l}\text { Foetal exposure } \\
\text { during pregnancy }\end{array}$ & 54 & $\begin{array}{l}18.3 \\
(13.88- \\
24.12)^{*}\end{array}$ & $\begin{array}{l}17.11 \\
(805.55)^{*}\end{array}$ & $\begin{array}{l}3.72 \\
(2.30)^{*}\end{array}$ & 204 & $\begin{array}{l}1.30 \\
(1.14- \\
1.50)^{*}\end{array}$ & $\begin{array}{l}1.30 \\
(14.12)^{*}\end{array}$ & $\begin{array}{l}2.33 \\
(2.30)^{*}\end{array}$ \\
\hline Premature baby & 1 & $\begin{array}{l}0.79 \\
(0.11- \\
5.65)\end{array}$ & $\begin{array}{l}0.79 \\
(0.05)\end{array}$ & $\begin{array}{l}0.18 \\
(0.28)\end{array}$ & 123 & $\begin{array}{l}1.98 \\
(1.66- \\
2.37)^{*}\end{array}$ & $\begin{array}{l}1.98 \\
(58.22)^{*}\end{array}$ & $\begin{array}{l}0.38 \\
(0.36)^{*}\end{array}$ \\
\hline $\begin{array}{l}\text { Abortion } \\
\text { spontaneous }\end{array}$ & 10 & $\begin{array}{l}5.39 \\
(2.85- \\
4.09)^{*}\end{array}$ & $\begin{array}{l}5.33 \\
(31.04)^{*}\end{array}$ & $\begin{array}{l}1.93 \\
(1.83)^{*}\end{array}$ & 80 & $\begin{array}{l}0.86 \\
(0.69- \\
1.07)\end{array}$ & $\begin{array}{l}0.86 \\
(1.71)\end{array}$ & $\begin{array}{l}0.97 \\
(0.94)\end{array}$ \\
\hline $\begin{array}{l}\text { Foetal growth } \\
\text { restriction }\end{array}$ & 25 & $\begin{array}{l}120.7 \\
(80.93- \\
180.08)^{*}\end{array}$ & $\begin{array}{l}116.93 \\
(2736.87)^{*}\end{array}$ & $\begin{array}{l}4.42 \\
(4.30)^{*}\end{array}$ & 16 & $\begin{array}{l}1.50 \\
(0.92- \\
2.45)\end{array}$ & $\begin{array}{l}1.50 \\
(2.17)\end{array}$ & $\begin{array}{l}0.22 \\
(0.19)\end{array}$ \\
\hline $\begin{array}{l}\text { Low birth weight } \\
\text { baby }\end{array}$ & 1 & $\begin{array}{l}3.69 \\
(0.52- \\
26.20)\end{array}$ & $\begin{array}{l}3.68 \\
(0.19)\end{array}$ & $\begin{array}{l}0.65 \\
(0.54)\end{array}$ & 6 & $\begin{array}{l}0.44 \\
(0.20- \\
1.00)\end{array}$ & $\begin{array}{l}0.44 \\
(3.62)\end{array}$ & $\begin{array}{l}1.05 \\
(1.00)\end{array}$ \\
\hline Stillbirth & 1 & $\begin{array}{l}4.28(0.60- \\
30.46)\end{array}$ & $\begin{array}{l}4.28 \\
(0.30)\end{array}$ & $\begin{array}{l}0.70 \\
(0.58)\end{array}$ & 9 & $\begin{array}{l}0.78 \\
(0.40- \\
1.49)\end{array}$ & $\begin{array}{l}0.78 \\
(0.38)\end{array}$ & $\begin{array}{l}0.33 \\
(0.28)\end{array}$ \\
\hline $\begin{array}{l}\text { Premature } \\
\text { rupture of } \\
\text { membranes }\end{array}$ & 0 & - & - & - & 9 & $\begin{array}{l}1.10 \\
(0.57- \\
2.11)\end{array}$ & $\begin{array}{l}1.10 \\
(0.01)\end{array}$ & $\begin{array}{l}0.16 \\
(0.06)\end{array}$ \\
\hline $\begin{array}{l}\text { Umbilical cord } \\
\text { abnormality }\end{array}$ & 0 & - & - & - & 1 & $\begin{array}{l}0.63 \\
(0.09- \\
4.48)\end{array}$ & $\begin{array}{l}0.63 \\
(0.00)\end{array}$ & $\begin{array}{l}0.37 \\
(0.24)\end{array}$ \\
\hline \multicolumn{9}{|c|}{ aPT: Preferred Terms } \\
\hline \multicolumn{9}{|c|}{${ }^{\mathrm{b}}$ Number of patients with adverse events } \\
\hline \multicolumn{9}{|c|}{$\begin{array}{l}{ }^{\mathrm{C}} \mathrm{ROR} \text { reporting odds ratio. The lower limits of the } 95 \% \mathrm{Cl} \text { of the ROR greater than } 1 \text { indicated } \\
\text { statistically significant RORs. }\end{array}$} \\
\hline \multicolumn{9}{|c|}{$\begin{array}{l}\text { d PRR proportional reporting ratio. PRR and } \chi^{2} \text { greater than } 2 \text { and } 4 \text { respectively indicated statistically } \\
\text { significant PRRs. }\end{array}$} \\
\hline \multicolumn{9}{|c|}{${ }^{\mathrm{e}}$ Information component. The signal was statistically significant when IC-2SD >0 } \\
\hline
\end{tabular}




\section{Discussion}

As far as we know, this is the first comparative safety study on FAERS that aimed to assess the reported AEs of darunavir and its boosted agents. Overall, four main findings emerged: (1) AEs related to darunavir exposure involve various organs or tissues, although some AEs occur more commonly than others. We found statistically significant signals in the liver, kidney, metabolic and nutritional system, endocrine system, eye, cardiac system, musculoskeletal system, nervous system, skin, and gastrointestinal tract. (2) Strongly positive signals related to mitochondrial toxicity and eye disorders (included diplopia, eyelid ptosis, and progressive external ophthalmoplegia) were revealed for the very first time. (3) The use of darunavir-containing agents may be related to some rare but severe AEs such as acute pancreatitis, serious dermatologic reactions (Stevens-Johnson Syndrome and exfoliative dermatitis) and angioedema. (4)Although darunavir is widely used in pregnant women, signals for adverse pregnancy outcomes (preterm birth, miscarriage, fetal growth restriction, low birth weight, stillbirth, premature rupture of fetal membranes, and abnormal umbilical cord) were detected in our study, which highlights its safety concern during pregnancy.

Hepatotoxicity is one of the commonly monitored safety profiles for darunavir during clinical practice ${ }^{4,8}$. According to the previous studies, some degree of serum aminotransferase elevations occurred in a high proportion of patients taking darunavir containing antiretroviral regimens. Moderate-to-severe elevations in serum aminotransferase levels are found in $3-10 \%$ of patients overall. Acute liver injury due to darunavir has been reported and the pattern of serum enzyme elevations is usually hepatocellular ${ }^{8}$. Our study uncovered positive signals for hepatocellular injury and elevation in serum hepatic enzymes which were consistent with the previous findings. Apart from hepatocellular injury, we also found darunavir can induce increased bilirubin, cholestasis, and jaundice which were not observed in clinical studies. In 2019, Yancheva N. ${ }^{9}$ reported a case of darunavir-related cholestatic hepatitis in an HIV patient in the third year of his combined antiretroviral therapy, and discontinuation of darunavir resulted in a progressive decrease in liver enzyme and bilirubin level. The cause of the hepatobiliary disorders from darunavir is not clearly known. The toxic intermediates may be the cause of some liver injury. It is worth noting that, except for hepatocellular injury, cholestasis should also be monitored when darunavir is prescribed. In coinfected individuals with hepatitis B or C, initiation of darunavir-based therapy lead to exacerbation of hepatitis $\mathrm{B}$ or $\mathrm{C}$ and serum aminotransferase elevations which need to be monitored prospectively ${ }^{10}$.

HIV infection has been associated with both acute kidney injury (AKI $)^{11}$ and chronic kidney disease $(C K D)^{12}$. It is hypothesized that HIV-associated nephropathy (HIVAN) involved direct infection of kidney epithelial cells by HIV with subsequent expression of HIV genes in a genetically susceptible host. The introduction of ART has reduced the incidence of end-stage renal disease (ESRD) attributed to HIVAN. A recent study suggested that darunavir can directly prevent kidney injury by suppressing HIV-induced upregulation of immune response genes in human kidney cells which were independent of inhibition of HIV 
protease. Nevertheless, in our study, 6 positive signals of the renal and urinary system were detected, which presented as AKI, renal impairment, blood creatinine increased, glomerular filtration rate decreased, proteinuria, and renal tubular necrosis. It was showed that cobicistat inhibits tubular secretion of creatinine without affecting actual renal glomerular function ${ }^{13}$. This should be considered when interpreting changes in blood creatinine in patients initiating darunavir/cobicistat. Besides, our study uncovered an association of darunavir with rhabdomyolysis, which might be one of the causes of kidney injury. On the other hand, we should take caution explaining the significant signal of darunavir in renal injury. Since HIVAN is one of the complications in advanced HIV disease, the main manifestations of which were heavy proteinuria and a decline in kidney function ${ }^{14}$. In accord with this assumption, drug resistance and treatment failure are significantly noted in the analysis, which implicated the occurrence of advanced HIV disease.

Our findings showed a disproportionate association with hypertriglyceridemia, hypercholesteremia, and hypokalemia. It was consistent with the previous findings that exposure to certain PIs can cause an adverse change in the lipid profile ${ }^{15}$. One study suggested that ritonavir-boosted darunavir and atazanavir rather than raltegravir lead to increases in total cholesterol, triglycerides, and low-density lipoprotein cholesterol (LDL-C $)^{16}$. In a pooled subgroup analysis of the clinical trials of boosted darunavir, $15 \%$ of patients developed elevated triglyceride levels compared with $7 \%$ percent in the comparator $\mathrm{PI}$ arms ${ }^{17}$. Baker also suggested that initiation of ARTs (including darunavir) increased the levels of total cholesterol and LDL-C ${ }^{18}$.

The signal of lipodystrophy, which has been associated with abnormalities in glucose and lipid metabolism, was extremely strong in our study. Lipodystrophy can be manifested as lipoatrophy or fat accumulation, and it was estimated that $10-80 \%$ of HIV patients developed these changes ${ }^{19,20}$. Data suggested that exposure to certain nucleoside reverse transcriptase inhibitors (NRTIs) is the major factor associated with lipoatrophy ${ }^{20}$. Some studies showed that PIs may act synergistically with NRTIs ${ }^{21}$, and therapy with PIs alone does not appear to lead to lipoatrophy ${ }^{22}$. Fat accumulation has been described since the introduction of combination ART, which was initially thought to be lead by the use of protease inhibitor therapy ${ }^{23}$. However, in studies that have replaced PIs with alternative ART, there has been no observed decrease in visceral fat ${ }^{24}$. A study showed that body fat tissue increased in patients on darunavir/ritonavir monotherapy and darunavir/ritonavir plus NRTIs, with no difference between the $\mathrm{arms}^{25}$.

Hyperglycemia is another positive signal identified in our study. In animal models, studies of HIV-negative volunteers given PIs, and clinical trials of PIs have all demonstrated insulin resistance with these agents $^{26}$. One possible explanation for the association is that PIs can direct down-regulation of the glucose transporter-4, the major transporter of glucose into fat cells, and cardiac and skeletal muscle ${ }^{27}$. It was suggested that darunavir-based ART in those patients who discontinued protease inhibitor therapy, hyperglycemia persisted in some cases ${ }^{28}$. Since HIV-positive persons are at increased risk for premature cardiovascular disease (CVD) ${ }^{29}$, and atherosclerotic disease accounts for a substantial proportion of HIV- 
related CVD, dyslipidemia and hyperglycemia caused by darunavir can adversely affect the risk factors for CVD. However, the association between darunavir or atazanavir administration and increased risk of myocardial infarction or stroke has not been established which was seen with other agents from this class $^{30}$.

Hypokalemia (serum potassium $\otimes 3.5 \mathrm{mEq} / \mathrm{L}$ ) is common in AIDS inpatients, usually due to infectious diarrhea, vomiting, or AIDS-related intestinal disease ${ }^{31}$. Hypokalemia directly caused by darunavir has not been reported, but it was suggested that diarrhea and vomiting were the most common adverse reactions of darunavir ${ }^{28}$, which we presumed might to be the cause of hypokalemia.

Adrenal suppression and adrenal dysfunction were found related to the use of darunavir-containing agents. In the early AIDS epidemic, adrenal disorders in HIV-infected individuals were often a consequence of opportunistic infections, neoplasms, or concomitant systemic illness, the morbidity of which declined rapidly due to potent antiretroviral therapy. The possible explanation of darunavircontaining agents induced adrenal disorder identified in our study may be due to drug-drug interaction of pharmacokinetic boosters with exogenous glucocorticoids ${ }^{32}$. Glucocorticoids, including nasal, inhaled, intra-articular, or topical ocular preparations, were widely used in HIV patients for non-AIDS-related conditions that occur more frequently and at a younger age than in uninfected persons ${ }^{33}$. latrogenic Cushing's syndrome can result from the co-administration of ritonavir or cobicistat and synthetic glucocorticoids given by any route ${ }^{34,35}$. The effects of these boosters on cytochrome P450 lead to prolongation of the half-life of the latter. The resultant high plasma levels of glucocorticoid cause Cushing's syndrome and suppression of endogenous adrenocorticotrophic hormone and secondary adrenal insufficiency. In a retrospective study of 171 patients, 9 cases developed secondary adrenal insufficiency after receiving $\geq 1$ local steroid injection, all of which occurred among the 81 patients on $\mathrm{PIs}^{36}$. Corticosteroid regardless of the route should be used with great caution and close monitoring in HIV-infected patients on Pls.

Our study revealed a strong association of mitochondrial toxicity and darunavir $(\mathrm{ROR}=171.92, \mathrm{PRR}=$ $136.03, I C=6.08$ ) that has not been reported previously. Mitochondrial toxicity has been recognized as a major adverse effect of the treatment of HIV infection with NRTIs ${ }^{37}$, but not darunavir or other PIs. The clinical expression of mitochondrial disorders is extremely variable, and organs and tissues highly related to oxidative phosphorylate (muscles and neuro for instance) are mostly easily involved. Muscle symptoms included exercise intolerance, fatigue, muscle weakness, elevated serum creatine kinase, myalgia, or, less often, rhabdomyolysis ${ }^{38}$. It is not surprising to find that, increased creatine phosphokinase and rhabdomyolysis are both positive signals in our study, which were presumed to be the clinical expression of mitochondrial toxicity of darunavir. Increased creatine phosphokinase and rhabdomyolysis were recorded adverse events in the label, and our study provided a possible explanation for the cause of these AEs. 
Another novel AEs inferred to be associated with mitochondrial toxicity of darunavir were eye disorders ${ }^{39}$, and they included diplopia, eyelid ptosis, and progressive external ophthalmoplegia (PEO). Among them, the signal of PEO showed a significantly high strength $(R O R=1761.17, P R R=1753.15 \square \mathrm{IC}=3.54)$. $\mathrm{PEO}$ is a myopathic alteration of slow progression which affects extrinsic ocular muscles; ptosis of the eyelid being the most characteristic sign. Some cases present as eyeball movement disorder, and progress to immobilization of the eye. PEO can be induced by trauma, toxin, heritable disorder, degeneration, and masses, and is one of the clinical phenotypes of mitochondrial myopathies ${ }^{40}$. We speculated that darunavir induced eye disorders through mitochondrial toxicity, although the relationship had to be confirmed with rigorous studies.

There is little doubt that mitochondrial toxicity is the major cause of NRTIs-induced myopathy, and neuropathy ${ }^{41}$, and we can't help but speculate the newly found AEs with nervous system disorders (neuropathy and peripheral neuropathy) of darunavir in our study might also be related to mitochondrial toxicity. However, this speculation needs to be further investigated. While the pathogenesis of NRTIs induced mitochondrial toxicity has been well known, which is by inhibiting mtDNA enzyme polymerasegamma, thus resulting in organelle dysfunction and impairment of oxidative phosphorylation ${ }^{42}$, the mechanism of Pls induced mitochondrial toxicity has not been revealed.

In our study, we found generalized rash, pruritus, exfoliative dermatitis and Stevens-Johnson Syndrome (SJS) were positive signals in the skin and subcutaneous tissue. In clinical trials, rash (all grades) occurred in $16 \%$ of subjects treated with darunavir. Rashes were generally mild-to-moderate, self-limited maculopapular skin eruptions ${ }^{43}$. Severe skin rash, including erythema multiforme and SJS has also been reported, with some accompanied by fever and elevations ofaminotransferase ${ }^{44}$. The discontinuation rate due to rash was $0.3 \%{ }^{28}$. SJS are severe mucocutaneous reactions, most commonly triggered by medications. The incidence of SJS is 100 -fold higher among HIV individuals than in the general population ${ }^{45}$. The reasons for the susceptibility are not fully understood, although exposure to multiple medications, immune dysregulation, and the presence of concomitant infections may contribute ${ }^{46}$. Our study brought to the forefront again the risk of severe adverse skin reactions caused by darunavir, which should be closely monitored.

Our study identified diarrhea, gastrointestinal disorder, esophageal candidiasis, and acute pancreatitis as positive signals in the gastrointestinal system. Diarrhea is one of the most commonly reported adverse reactions for darunavir, involving more than $10 \%$ of individuals ${ }^{47}$. Esophageal candidiasis, which is typically seen in patients with HIV who have advanced immunosuppression, may not be directly related to the administration of darunavir, but rather to the failure of antiviral therapy ${ }^{48}$. This inference is supported by the finding of the two strongly positive signals of drug resistance and therapy failure in our study. Acute pancreatitis induced by darunavir-based ARTs has been reported previously ${ }^{49}$. Hypertriglyceridemia and hypercholesteremia related to darunavir may play a role in the occurrence of acute pancreatitis. Besides, it was suggested that mitochondrial toxicity may be the cause of NRTI-induced pancreatitis ${ }^{50}$, 
the possibility cannot be ruled out that acute pancreatitis is one of the manifestations of darunavirinduced mitochondrial toxicity.

Protease inhibitors have been a key component of HIV therapy in pregnant women for about 25 years. In 2016 DHHS guidelines, darunavir/ritonavir replaced lopinavir/ritonavir as a recommended agent due to its potent antiretroviral activity, low propensity for resistance development, and a lower rate of causing lipid abnormality during pregnancy ${ }^{51}$. It was found that the fetal transfer rate of darunavir was $12-16 \%$, and a mean concentration of $132 \pm 32 \mathrm{ng} / \mathrm{mL}$ was identified in the fetal compartment ${ }^{52}$. Although fetal concentrations are much lower than those in maternal plasma, this can still expose the fetus to a significant concentration of the drug. Such exposure may provide the benefit of pre-exposure prophylaxis, but it could also lead to toxicity. Although teratogenicity has not been identified in animal studies ${ }^{28}$, no well-designed controlled trials have been performed in humans. The antiviral pregnancy registry reported that the risk of birth defects did not increase following darunavir exposure ${ }^{53}$, and darunavir could even play a protective role in the development of microcephaly in children who were HIV-exposed but uninfected $^{54}$. Our study showed strongly positive signals for darunavir in terms of premature baby, spontaneous abortion, foetal growth restriction, low birth weight baby, stillbirth, premature rupture of membranes, and umbilical cord abnormality. In the previous studies, preterm birth and low birth weight were the most commonly reported adverse events after pregnancy exposure to $\mathrm{PIs}^{55,56}$. One study suggested that prematurity was independently associated with ritonavir-boosted PI therapy during pregnancy ${ }^{57}$. We further detected signals for darunavir/ritonavir and darunavir/cobicistat respectively, identifying positive signal for darunavir/ritonavir only in prematurity, and darunavir/cobicistat in abortion spontaneous and feotal growth restriction. The result further verified that preterm birth may be more associated with ritonavir. Since the combination of darunavir/cobicistat is not currently recommended during pregnancy due to a lack of pharmacokinetic and safety data for cobicistat in pregnant women ${ }^{51}$, the difference of these two combinations for the offspring need to be further studied.

The data mining of FAERS database is considered to be a valuable tool to evaluate the medication safety profile. Despite some steps were taken to make the results more reliable, such as report cleaning and utilizing three methodologies to reduce the incidence of false-positive signals, the following limitations of our study need to be noticed: (1) we derived ROR, PRR, and IC values based on the reported frequency of drug-event combinations for the studies drug, and were adjusted based on the rates reported by other drugs and the rates of all other AEs reported for the studied drug. The value indicated an increased risk of $A E$ reporting and not a risk of AE occurrence. (2) The FAERS database is subject to various biases such as under-reporting, over-reporting, duplicates, unverified source of submitted data, missing information. (3) The certainty that the drug is in fact responsible for the reported event is absent. This is particularly true for antiretroviral agents in HIV patients since HIV infection per se can induce a higher risk of multisystem complications and are generally treated with a combination of antiviral drugs. (4) Except for pregnancy and perinatal conditions, the signal mining was not carried out separately for darunavir, darunavir/ritonavir, and darunavir/cobicistat, making it impossible to distinguish AEs resulted from darunavir and boosters. 


\section{Conclusions}

The safety profile of darunavir containing agents was reviewed using the AEs submitted to the FAERS. Base on the 10756 reports, AEs with darunavir and its boosted agents took place in many organs/tissues. A strongly positive signal related to mitochondrial toxicity was identified and was presumed to be associated with the occurrence of AEs in multiple systems (eye, muscle, nerve, etc.). Darunavir was shown to be associated with multiple adverse pregnancy conditions. The usefulness of pharmacovigilance research should be corroborated with the real-world FAERS data; however, further clinical trials are required to confirm our findings.

\section{Methods}

Data sources. We conducted a retrospective pharmacovigilance study using data from the FAERS database covering the period from July 2006 to December 2019 through the OpenVigil FDA platform. OpenVigil FDA, a pharmacovigilance tool, was to facilitate access and use of big important FDA public datasets by developers, researchers, and the public through harmonization of data across disparate FDA datasets provided via application programming interfaces (APIs) toeffectively support post-market research. To ensure data integrity, AE reports for "darunavir", "darunavir/ritonavir" or "darunavir/cobicistat" were analyzed.

Definition of AEs. The informatic structure of the FAERS database adheres to the international safety reporting guidance issued by the International Conference on Harmonisation (ICH E2B). AEs are coded using preferred terms (PTs) in the Medical Dictionary for Regulatory Activities (MedDRA) terminology. This study relied on definitions used by MedDRA. First, disproportionality analysis and Bayesian analysis were performed using all SOCs to identify the safety profiles of darunavir. Secondly, AE listings were extracted for darunavir, After gathering the overall reports, further disproportionality analysis and Bayesian analysis of PT levels was based on the signal strength and the number of reported AEs associated with darunavir in different systems. Two researchers classified the AEs reports in terms of SOCs and PTs, and collect clinical characteristics of the patient, including gender, age, AE outcome, and type of reporter, respectively. Death, life-threatening adverse drug experience, inpatient/prolonged hospitalization, and significant disability/incapacity were defined as serious adverse events (SAEs).

Data mining algorithm and statistical analysis. Descriptive analyses were conducted to summarize the clinical characteristics of the patients with darunavir-associated AEs collected from the FAERS database. In this study, the signals of disproportionate reporting (SDR) and Bayesian confidence propagation neural network (BCPNN) were generated by calculating the reporting odds ratio (ROR), proportional reporting ratio (PRR), information component(IC). These methods were based on two-by-two contingency (Table1). An association between drug and an AEs was identified when all the three algorithms were positive. The equations and criteria for the algorithms are shown in Table $2^{58-60}$. Statistical signification was declared at $\mathrm{P}<0.05$ with $95 \%$ confidence intervals $(\mathrm{Cls})$. The analyses were conducted using the Microsoft EXCEL 2010 and SPSS 13.0 statistical software. 
Table 1

Two-by-two contingency table for disproportionality analyses

\begin{tabular}{|llll|}
\hline & Reports with the target AEs & All other AEs & Total \\
\hline Reports with the target drug & $a$ & $b$ & $a+b$ \\
\hline All other drugs & $c$ & $d$ & $c+d$ \\
\hline Total & $a+c$ & $b+d$ & $a+b+c+d$ \\
\hline
\end{tabular}

Table 2

Summary of major algorithms used for signal detection

\begin{tabular}{|lll|}
\hline Algorithms & Equation & Criteria \\
\hline ROR & ROR $=(a / b) /(c / d)$ & $95 \% C l>1, N \geq 3$ \\
PRR & PRR $=(a /(a+c)) /(b /(b+d))$ & $P R R \geq 2, x 2 \geq 4, N \geq 3$ \\
BCPNN & $I C=\log ^{2} a(a+b+c+d) /((a+c)(a+b))$ & IC-2SD $>0$ \\
\hline
\end{tabular}

\section{Declarations}

\section{Author contributions}

All the authors were involved in the study. X.T., Y.Y. and L.C.concept and design, acquisition of data, analysis and interpretation of data, manuscript preparation; K.W. and Y.J.: analysis and interpretation of data; G.H.: revision of the manuscript.

\section{Competing interests}

The authors declare no competing interests.

\section{Additional information}

Correspondence and requests for materials should be addressed to L.C.

\section{References}

1. Guidelines for managing. advanced HIV disease and rapid initiation of antiretroviral therapy, July 2017 (World Health Organization, Geneva, 2017).

2. Saag, M. S. et al. Antiretroviral Drugs for Treatment and Prevention of HIV Infection in Adults: 2018 Recommendations of the International Antiviral Society-USA Panel. JAMA. 320, 379-396 https://doi.org/10.1001/jama.2018.8431 (2018). 
3. Global, A. I. D. S. 2016. Geneva: UNAIDS; 2016 (http://www.unaids.org/en/resources/ documents/2016/Global-AIDS-update-2016, accessed 19 May 2017).

4. Vispo, E. Warning on hepatotoxicity of darunavir. AIDS Rev. 10, 63 (2008).

5. Introcaso, C. E., Hines, J. M. \& Kovarik, C. L. Cutaneous toxicities of antiretroviral therapy for HIV. Journal of the American Academy of Dermatology. 63, 549-561 https://doi.org/10.1016/j.jaad.2010.01.061 (2010).

6. US Department of Health and Human Services (HHS) Panel on Treatment of Pregnant Women with HIV Infection and Prevention of Perinatal Transmission. Recommendations for the use of antiretroviral drugs in pregnant women with HIV infection and interventions to reduce perinatal HIV transmission in the United States. http://aidsinfo.nih.gov/contentfiles/lvguidelines/PerinatalGL.pdf. Updated December 24, 2019. Accessed January 2, 2020.

7. Antiretroviral pregnancy registry steering committee. The Antiretroviral pregnancy registry:interim report-1 January 1989 through 31 July 2015. 2015.

http://www.apregistry.com/forms/interim_report.pdf.

8. LiverTox: Clinical and Research Information on DrugInduced Liver Injury [Internet]. Bethesda (MD): National Institute of Diabetes and Digestive and Kidney Diseases; 2012-. Darunavir. [Updated 2017 Sep 1].

9. Yancheva, N. \& Tzonev, R. A case of late presentation of darunavir-related cholestatic hepatitis. Int J STD AIDS. 30, 620-622 https://doi.org/10.1177/0956462419826723 (2019).

10. Rivero, A., Camacho, A., Perez-Camacho, I. \& Torre-Cisneros, J. [Darunavir in HIV/HVC/HVB coinfection]. Enferm Infecc Microbio/ Clin. 26 Suppl 10, 37-42 https://doi.org/10.1016/s0213005x(08)76552-2 (2008).

11. Wyatt, C. M., Arons, R. R., Klotman, P. E. \& Klotman, M. E. Acute renal failure in hospitalized patients with HIV: risk factors and impact on in-hospital mortality. AIDS. 20, 561-565 https://doi.org/10.1097/01.aids.0000210610.52836.07 (2006).

12. Estrella, M. M. et al. Chronic kidney disease and estimates of kidney function in HIV infection: a cross-sectional study in the multicenter AIDS cohort study. J Acquir Immune Defic Syndr. 57, 380386 https://doi.org/10.1097/QAl.0b013e318222f461 (2011).

13. Casado, J. L. et al. Evaluation of kidney function in HIV-infected patients receiving an antiretroviral regimen containing one or two inhibitors of the tubular secretion of creatinine. HIV Med. 20, 648-656 https://doi.org/10.1111/hiv.12784 (2019).

14. Bige, N. et al. Presentation of HIV-associated nephropathy and outcome in HAART-treated patients. Nephrol Dial Transplant. 27, 1114-1121 https://doi.org/10.1093/ndt/gfr376 (2012).

15. Fontas, E. et al. Lipid profiles in HIV-infected patients receiving combination antiretroviral therapy: are different antiretroviral drugs associated with different lipid profiles? J Infect Dis. 189, 1056-1074 https://doi.org/10.1086/381783 (2004).

16. Ofotokun, I. et al. Comparison of the metabolic effects of ritonavir-boosted darunavir or atazanavir versus raltegravir, and the impact of ritonavir plasma exposure: ACTG 5257. Clin Infect Dis. 60, 
1842-1851 https://doi.org/10.1093/cid/civ193 (2015).

17. Clotet, B. et al. Efficacy and safety of darunavir-ritonavir at week 48 in treatment-experienced patients with HIV-1 infection in POWER 1 and 2: a pooled subgroup analysis of data from two randomised trials. Lancet. 369, 1169-1178 https://doi.org/10.1016/S0140-6736(07)60497-8 (2007).

18. Baker, J. V. et al. Changes in Cardiovascular Disease Risk Factors With Immediate Versus Deferred Antiretroviral Therapy Initiation Among HIV-Positive Participants in the START (Strategic Timing of Antiretroviral Treatment) Trial. J Am Heart Assoc. 6, https://doi.org/10.1161/JAHA.116.004987 (2017).

19. Mallon, P. W., Miller, J., Cooper, D. A. \& Carr, A. Prospective evaluation of the effects of antiretroviral therapy on body composition in HIV-1-infected men starting therapy. AIDS. 17, 971-979 https://doi.org/10.1097/00002030-200305020-00005 (2003).

20. Heath, K. V. et al. Lipodystrophy-associated morphological, cholesterol and triglyceride abnormalities in a population-based HIV/AIDS treatment database. AIDS. 15, 231-239 https://doi.org/10.1097/00002030-200101260-00013 (2001).

21. Dube, M. P. et al. Glucose metabolism, lipid, and body fat changes in antiretroviral-naive subjects randomized to nelfinavir or efavirenz plus dual nucleosides. AIDS. 19, 1807-1818 https://doi.org/10.1097/01.aids.0000183629.20041.bb (2005).

22. Wohl, D. A. et al. Current concepts in the diagnosis and management of metabolic complications of HIV infection and its therapy. Clin Infect Dis. 43, 645-653 https://doi.org/10.1086/507333 (2006).

23. Martinez, E. et al. Risk of lipodystrophy in HIV-1-infected patients treated with protease inhibitors: a prospective cohort study. Lancet. 357, 592-598 https://doi.org/10.1016/S0140-6736(00)04056-3 (2001).

24. Lake, J. E. et al. Switch to Raltegravir From Protease Inhibitor or Nonnucleoside ReverseTranscriptase Inhibitor Does not Reduce Visceral Fat In Human Immunodeficiency Virus-Infected Women With Central Adiposity. Open Forum Infect Dis. 2, ofv059 https://doi.org/10.1093/ofid/ofv059 (2015).

25. Valantin, M. A. et al. Body fat distribution in HIV-infected patients treated for 96 weeks with darunavir/ritonavir monotherapy versus darunavir/ritonavir plus nucleoside reverse transcriptase inhibitors: the MONOI-ANRS136 substudy. HIV Med. 13, 505-515 https://doi.org/10.1111/j.14681293.2012.01004.x (2012).

26. Grinspoon, S. \& Carr, A. Cardiovascular risk and body-fat abnormalities in HIV-infected adults. N Engl J Med. 352, 48-62 https://doi.org/10.1056/NEJMra041811 (2005).

27. Rudich, A., Ben-Romano, R., Etzion, S. \& Bashan, N. Cellular mechanisms of insulin resistance, lipodystrophy and atherosclerosis induced by HIV protease inhibitors. Acta Physiol Scand. 183, 7588 https://doi.org/10.1111/j.1365-201X.2004.01383.x (2005).

28. Prezista (darunavir) (prescribing information). Titusville, NJ: Janssen Therapeutics; May 2019.

29. Freiberg, M. S. et al. HIV infection and the risk of acute myocardial infarction. JAMA Intern Med. 173, 614-622 https://doi.org/10.1001/jamainternmed.2013.3728 (2013). 
30. Monforte, A. et al. Atazanavir is not associated with an increased risk of cardio- or cerebrovascular disease events. AIDS. 27, 407-415 https://doi.org/10.1097/QAD.0b013e32835b2ef1 (2013).

31. Musso, C. G., Belloso, W. H. \& Glassock, R. J. Water, electrolytes, and acid-base alterations in human immunodeficiency virus infected patients. World J Nephrol. 5, 33-42 https://doi.org/10.5527/wjn.v5.i1.33 (2016).

32. Makaram, N., Russell, C. D., Roberts, S. B., Stevens, J. \& Macpherson, G. Exogenous steroid-induced hypoadrenalism in a person living with HIV caused by a drug-drug interaction between cobicistat and intrabursal triamcinolone. BMJ Case Rep. 11, https://doi.org/10.1136/bcr-2018-226912 (2018).

33. Schouten, J. et al. Cross-sectional comparison of the prevalence of age-associated comorbidities and their risk factors between HIV-infected and uninfected individuals: the AGEhIV cohort study. Clin Infect Dis. 59, 1787-1797 https://doi.org/10.1093/cid/ciu701 (2014).

34. Kedem, E., Shahar, E., Hassoun, G. \& Pollack, S. latrogenic Cushing's syndrome due to coadministration of ritonavir and inhaled budesonide in an asthmatic human immunodeficiency virus infected patient. J Asthma. 47, 830-831 https://doi.org/10.3109/02770903.2010.485666 (2010).

35. Rainsbury, P. G. et al. Ritonavir and Topical Ocular Corticosteroid Induced Cushing's Syndrome in an Adolescent With HIV-1 Infection. Pediatr Infect Dis J. 36, 502-503 https://doi.org/10.1097/INF.0000000000001534 (2017).

36. Hyle, E. P. et al. High frequency of hypothalamic-pituitary-adrenal axis dysfunction after local corticosteroid injection in HIV-infected patients on protease inhibitor therapy. J Acquir Immune Defic Syndr. 63, 602-608 https://doi.org/10.1097/QAl.0b013e31829b662b (2013).

37. Cossarizza, A. \& Moyle, G. Antiretroviral nucleoside and nucleotide analogues and mitochondria. AIDS. 18, 137-151 https://doi.org/10.1097/00002030-200401230-00002 (2004).

38. Moyle, G. Clinical manifestations and management of antiretroviral nucleoside analog-related mitochondrial toxicity. Clin Ther. 22, 911-936 discussion 898 https://doi.org/10.1016/S01492918(00)80064-8 (2000).

39. Kisilevsky, E., Freund, P. \& Margolin, E. Mitochondrial disorders and the eye. Surv Ophthalmol. 65, 294-311 https://doi.org/10.1016/j.survophthal.2019.11.001 (2020).

40. McClelland, C., Manousakis, G. \& Lee, M. S. Progressive External Ophthalmoplegia. Curr Neurol Neurosci Rep. 16, 53 https://doi.org/10.1007/s11910-016-0652-7 (2016).

41. Brinkman, K., ter Hofstede, H. J., Burger, D. M., Smeitink, J. A. \& Koopmans, P. P. Adverse effects of reverse transcriptase inhibitors: mitochondrial toxicity as common pathway. AIDS. 12, 1735-1744 https://doi.org/10.1097/00002030-199814000-00004 (1998).

42. Brinkman, K. \& Kakuda, T. N. Mitochondrial toxicity of nucleoside analogue reverse transcriptase inhibitors: a looming obstacle for long-term antiretroviral therapy? Curr Opin Infect Dis. 13, 5-11 https://doi.org/10.1097/00001432-200002000-00002 (2000).

43. Introcaso, C. E., Hines, J. M. \& Kovarik, C. L. Cutaneous toxicities of antiretroviral therapy for HIV: part I. Lipodystrophy syndrome, nucleoside reverse transcriptase inhibitors, and protease inhibitors. J Am 
Acad Dermatol. 63, 549-561 quiz 561 - 542 https://doi.org/10.1016/j.jaad.2010.01.061 (2010).

44. Nishijima, T. et al. Skin rash induced by ritonavir-boosted darunavir is common, but generally tolerable in an observational setting. $J$ Infect Chemother. 20, 285-287 https://doi.org/10.1016/j.jiac.2014.01.004 (2014).

45. Mittmann, N. et al. Incidence of toxic epidermal necrolysis and Stevens-Johnson Syndrome in an HIV cohort: an observational, retrospective case series study. Am J Clin Dermatol. 13, 49-54 https://doi.org/10.2165/11593240-000000000-00000 (2012).

46. Rotunda, A., Hirsch, R. J., Scheinfeld, N. \& Weinberg, J. M. Severe cutaneous reactions associated with the use of human immunodeficiency virus medications. Acta Derm Venereol. 83, 1-9 https://doi.org/10.1080/00015550310002611 (2003).

47. Molina, J. M. et al. Safety and efficacy of darunavir (TMC114) with low-dose ritonavir in treatmentexperienced patients: 24-week results of POWER 3. J Acquir Immune Defic Syndr. 46, 24-31 https://doi.org/10.1097/QAl.0b013e3181359cfb (2007).

48. Wilcox, C. M., Straub, R. F. \& Clark, W. S. Prospective evaluation of oropharyngeal findings in human immunodeficiency virus-infected patients with esophageal ulceration. Am J Gastroenterol. 90, 19381941 (1995).

49. Orkin, C. et al. Efficacy and safety of switching from boosted protease inhibitors plus emtricitabine and tenofovir disoproxil fumarate regimens to single-tablet darunavir, cobicistat, emtricitabine, and tenofovir alafenamide at 48 weeks in adults with virologically suppressed HIV-1 (EMERALD): a phase 3, randomised, non-inferiority trial. Lancet HIV. 5, e23-e34 https://doi.org/10.1016/S23523018(17)30179-0 (2018).

50. Coghlan, M. E. et al. Symptomatic lactic acidosis in hospitalized antiretroviral-treated patients with human immunodeficiency virus infection: a report of 12 cases. Clin Infect Dis. 33, 1914-1921 https://doi.org/10.1086/323783 (2001).

51. Recommendations for use of antiretroviral drugs in pregnant HIV-1-infected women for maternal health and interventions to reduce perinatal HIV transmission in the United States. Rockville (MD): Panel on Treatment of HIV-Infected Pregnant Women and Prevention of Perinatal Transmission. 2016 Jun 7. Available at: https://aidsinfo.nih.gov/contentfiles/lvguidelines/perinatalgl.pdf.

52. Pope, R. Jr. \& Kashuba, A. Darunavir for use in pregnant women with HIV. Expert Rev Clin Pharmacol. 10, 1317-1327 https://doi.org/10.1080/17512433.2017.1390428 (2017).

53. Antiretroviral Pregnancy Registry Steering Committee. Antiretroviral Pregnancy Registry International Interim Report for 1 January 1989 through 31 January 2016. 2016. Wilmington, NC: Registry Coordinating Center. www.APRegistry.com. Accessed July 21, 2016.

54. Williams, P. L. et al. Association of maternal antiretroviral use with microcephaly in children who are HIV-exposed but uninfected (SMARTT): a prospective cohort study. Lancet HIV. 7, e49-e58 https://doi.org/10.1016/S2352-3018(19)30340-6 (2020).

55. Mesfin, Y. M., Kibret, K. T. \& Taye, A. Is protease inhibitors based antiretroviral therapy during pregnancy associated with an increased risk of preterm birth? Systematic review and a meta- 
analysis. Reprod Health. 13, 30 https://doi.org/10.1186/s12978-016-0149-5 (2016).

56. Powis, K. M. et al. Increased risk of preterm delivery among HIV-infected women randomized to protease versus nucleoside reverse transcriptase inhibitor-based HAART during pregnancy. $J$ Infect Dis. 204, 506-514 https://doi.org/10.1093/infdis/jir307 (2011).

57. Sibiude, J. et al. Premature delivery in HIV-infected women starting protease inhibitor therapy during pregnancy: role of the ritonavir boost? Clin Infect Dis. 54, 1348-1360 https://doi.org/10.1093/cid/cis198 (2012).

58. Sakaeda, T., Tamon, A., Kadoyama, K. \& Okuno, Y. Data mining of the public version of the FDA Adverse Event Reporting System. Int J Med Sci. 10, 796-803 https://doi.org/10.7150/ijms.6048 (2013).

59. Poluzzi, E., Raschi, E., Moretti, U. \& De Ponti, F. Drug-induced torsades de pointes: data mining of the public version of the FDA Adverse Event Reporting System (AERS). Pharmacoepidemiol Drug Saf. 18, 512-518 https://doi.org/10.1002/pds.1746 (2009).

60. Ahmed, l. et al. Bayesian pharmacovigilance signal detection methods revisited in a multiple comparison setting. Stat Med. 28, 1774-1792 https://doi.org/10.1002/sim.3586 (2009). 